\title{
John Rawls e Charles Taylor: Liberalismo igualitário e comunitarismo/multiculturalismo. Um diálogo possível?
}

Rosangela da Silva ${ }^{1}$

Francioli Bagatin ${ }^{2}$

Resumo: O liberalismo igualitário de John Rawls é um dos temas centrais das discussões produzidas no interior da teoria política contemporânea. Sua teoria de justiça - apresentada em sua obra Uma teoria de justiça, publicada em 1971 - foi elaborada tendo como premissa o fato de que as sociedades contemporâneas são complexas e plurais. Diante de sociedades como essas, qual seria a teoria de justiça mais adequada? Sabendo que seus indivíduos são livres, iguais e racionais, ele afirma que a as regras de associação nas referidas sociedades deveriam ser pautadas na ideia de justiça como equidade. Sua teoria suscitou um grande conjunto de debates, das mais diferentes matrizes teóricas, inclusive internamente no liberalismo. Neste trabalho será apresentada apenas uma delas, a do teórico Charles Taylor, elaborada a partir de uma vertente do comunitarismo, o multiculturalismo. As contribuições desse autor vêm no sentido de fazer uma crítica à teoria normativa rawlsiana, que é acusada de não dar conta da diversidade das sociedades, pois ainda está presa ao sujeito construído pelo iluminismo, que é adjetivado como abstrato. Taylor, por sua vez, se insere no debate, retomando o conceito de reconhecimento, debate o qual está muito associado às discussões acerca da identidade de sujeitos e grupos sociais e da valorização de suas particularidades enquanto tal.

PALAVRAS-CHAVE: Liberalismo igualitário. Multiculturalismo. Justiça. Democracia.

Doutoranda no Programa de Pós-Graduação em Ciências Sociais. Faculdade de Ciências e Letras, Araraquara (Unesp). Bolsista Capes DS. E-mail: ro.toledo84@hotmail.com

2 Mestre em Ciências Sociais pela UNIOESTE/2018. Graduada em Ciências Sociais (Bacharelado) pela UNIOESTE/2016. Graduada em Ciências Sociais (Licenciatura) pela UNIOESTE/2015. Especialista em Planejamento, Gestão e Avaliação de Políticas Públicas pela UNIOESTE/2013. Graduada em Direito pela Universidade Paranaense UNIPAR/1998. Especialista em Direito Processual Civil pela UFPR/2001. Docente do Centro de Ciências Sociais Aplicadas da UNIOESTE campus Francisco Beltrão. E-mail: franbng@hotmail.com 


\title{
John Rawls and Charles Taylor: Equal liberalism and communitarianism/multiculturalism. A possible dialogue?
}

\begin{abstract}
Egalitarian liberalism of John Rawls is a central theme of the discussions produced by contemporary political theory. His theory of justice - presented in his work Theory of Justice published in 1971 - was elaborated having as premise the fact the contemporary societies are complex and plural. That said, in complex and plural societies what would be the most appropriate theory of justice? Knowing that his individuals are free, equal and rational, he says that the rules of association in those societies should be guided by the idea of justice as equity. His theory raised a lot of debates, of the most different theoretical matrices, including internally to liberalism. In this work will be presented only one of them, that of the theorethician Charles Taylor, elaborated elaborated from a strand of communitarianism, multiculturalism. The contributions of this author criticize the Rawlsian normative theory that is accused of failing to account for the diversity of societies, because it's still attached to the subject constructed by the Enlightenment, which is called abstract. Taylor, on the other hand is part of the debate, returning the concept of recognition, a debate witch is associated with discussions about identity of subjects and social groups and the valorization of their particularities as such.
\end{abstract}

Keywords: Egalitarian liberalism. Multiculturalism. Justice. Democracy. 


\section{Introdução ${ }^{3}$}

A discussão acerca da teoria política contemporânea não pode ser feita sem passar pelo debate da teoria da justiça de John Rawls, explicitada inicialmente, em sua obra Uma teoria da justiça, publicada em 1971. É consenso também que as discussões suscitadas por essa obra, sejam análises que corroboram com elementos da perspectiva rawlsiana ou que a refutam, são também fundamentais para se entender esse debate.

O conjunto de críticas dirigidas a Uma teoria da justiça foi elaborado por autores filiados a diferentes vertentes, dentro do próprio liberalismo - como, por exemplo, Ronald Dworkin e Robert Nozick (libertarismo); como também a partir do marxismo analítico, que pode ser representado pela teoria socialista de G. A. Cohen e, por fim, do comunitarismo. Dada a grande dimensão das críticas elaboradas, pretende-se, neste trabalho, apresentar, apenas em linhas gerais, os autores acima citados para, posteriormente, promover uma reflexão acerca dos elementos centrais da teoria rawlsiana acerca da sua teoria da justiça, influenciada pela política do universalismo, e a crítica elaborada em relação a ela, a partir do multiculturalismo - enquanto uma das vertentes do comunitarismo, de Charles Taylor. Essa crítica está pautada na discussão acerca da importância do reconhecimento nas sociedades contemporâneas, que irá se fundamentar a partir das discussões via política da diferença.

\section{O liberalismo igualitário de Rawls: aspectos centrais da sua teoria de justiça}

A discussão elaborada por John Rawls, na obra Uma teoria da Justiça, conjuga filosofia política com teoria política normativa. Ele afirma que seu objetivo é elaborar uma teoria de justiça que seja a mais adequada para as sociedades democráticas contemporâneas, que são complexas e plurais. Sua visão pluralista se constrói em uma clara relação de oposição às perspectivas já existentes e dominantes, como a ideia de justiça utilitarista, em que o indivíduo busca "maximização de seu bem-estar, ao promover seus objetivos racionais o máximo possível" (RAWLS, 1997, p. 25). Nessa concepção teleológica, traduzida na busca de um fim último, as sociedades contabilizam a soma das satisfações a partir da análise das ações individuais que promoveram maior felicidade, no entanto, para esse autor, o problema reside no fato de que a princípio não importa como cada indivíduo participa dessa soma.

Apesar de a teoria de justiça de Rawls ter, como horizonte de análise, as sociedades contemporâneas, seus questionamentos não se diferem muito dos questionamentos dos filósofos políticos clássicos, como Platão e Aristóteles, que se perguntavam acerca de como se arranjava a vida da pólis, como se vivia ou deveria se viver, enfim, acerca de como se organizava a vida política. Para Aristóteles, por exemplo, a verdadeira vida e felicidade só se constituíam na pólis, através da participação na vida política. Havia uma relação entre a moral e os modos e costumes institucionalizados que se realizavam na experiência real da pólis e, dessa forma, a justiça também aí se realizaria, não só no plano privado, mas no coletivo, estabelecendo uma ligação entre o indivíduo e a pólis, de modo que só poderia haver justiça onde houvesse igualdade.

3 O presente trabalho foi realizado com apoio da Coordenação de Aperfeiçoamento de Pessoal de Nível Superior - Brasil (CAPES) - Código de Financiamento 001. 
O princípio da igualdade é um dos pilares que, na modernidade, dão sustentabilidade ao sistema político democrático. Tais debates foram recorrentes ao longo da história, tendo sido objeto de estudo de diversos filósofos, mas foi particularmente Aristóteles quem deu maior amplitude ao assunto. É na Ética a Nicômaco que podemos encontrar sua defesa do princípio da igualdade:

Se as pessoas não são iguais, não receberão coisas iguais; mas isso é origem de disputa e queixas (como quando iguais recebem partes desiguais, ou quando desiguais recebem partes desiguais). Ademais, isso se torna evidente pelo fato de que as distribuições devem ser feitas "de acordo com o mérito de cada um", pois todos concordam que o que é justo com relação à distribuição, também o deve ser com o mérito em um certo sentido (ARISTÓTELES, 2013, p.99-100).

Assim, segundo o pensamento aristotélico, o princípio da igualdade estaria diretamente ligado ao conceito de justiça, sendo que, nessa relação, para que exista justiça, a igualdade é fundamental. Segundo José Afonso da Silva: "Aristóteles vinculou a ideia de igualdade à ideia de justiça, mas, nele, trata-se de igualdade de justiça relativa que dá a cada um o que é seu" (2005. p.212). A igualdade, então, nessa concepção, consiste em tratar igualmente os iguais e desigualmente os desiguais, de modo que, se as pessoas não são iguais, de modo algum poderão receber coisas iguais, ou seja, as desigualdades existentes devem ser reconhecidas, de modo que sejam tratadas a fim de gerar a integração na sociedade dos indivíduos considerados desiguais. É com base nesse pensamento, então, que se estabelece o fundamento da justiça distributiva, pois, para estabelecer a igualdade, é preciso buscar a equidade. Entretanto, deve-se primeiro definir quem são os iguais e quem são os desiguais.

Se Aristóteles pensou o princípio da igualdade e de justiça ante a realidade da pólis, a diferença é que, como dito, Rawls está diante de sociedades complexas e plurais, e também pelo fato de se preocupar com a dimensão distributiva da justiça. E, aqui, a questão que se coloca é: Como se constrói uma ordem social que seja capaz de manter o pluralismo e que seja também justa?

Para Rawls, "a justiça é a primeira virtude das instituições sociais" (1997, p.3). Afirmada a primazia da justiça, ele se ocupa, então, da elaboração de uma teoria acerca dessa temática, a qual se propõe ser a mais adequada à análise das complexas sociedades contemporâneas. "Rawls quer responder à seguinte pergunta: qual é a concepção de justiça mais adequada para especificar os termos justos de cooperação entre cidadãos tidos como livres e iguais, racionais e razoáveis, membros cooperativos de uma sociedade ao longo da vida?” (FERES JÚNIOR, 2010, p.11).

A justiça como equidade se traduz na melhor concepção de justiça, segundo Rawls. A base dessa concepção reside na recuperação da teoria do contrato social, de Locke, Rousseau e Kant, dando ênfase à ideia de que os indivíduos estariam numa posição original de igualdade e definindo os princípios básicos que norteariam as regras fundamentais de sua associação (RAWLS, 1997). É sabido que o momento em que se estabelece o contrato nas teorias contratualistas clássicas é um momento hipotético, da mesma forma o é a posição original da qual fala Rawls. No entanto, no caso dos primeiros, antes do contrato, os indivíduos estão vivendo no estado de natureza e a instituição do contrato irá determinar uma forma específica de sociedade e de governo. Já na teoria rawlsiana, embora também se coloque a questão de pensar arranjos societários, o que está em questão é como indivíduos livres, iguais e racionais escolhem princípios de justiça que irão definir as suas regras de associação. 
O véu de ignorância, que pressupõe que os indivíduos na posição original não saibam qual é sua posição na sociedade, tanto no que se refere às questões econômicas e de status social, quanto acerca dos dotes e habilidades naturais, é o recurso de que Rawls lança mão para assegurar à sua concepção um ponto de partida igualitário. Nessas condições, sob o véu de ignorância, as escolhas são feitas em um ambiente de incertezas, por isso, ele afirma que, nesses casos, é recomendável aplicar a regra denominada de maximin, a qual indica que é razoável que os indivíduos livres optem por princípios que façam a distribuição igual, pois, já que não sabem qual é a sua posição real na sociedade, mesmo que venham a obter o pior resultado, teriam escolhido os princípios que melhor lhes protegeriam. Portanto, liberdade e igualdade são os princípios sob os quais assenta a teoria de justiça como a equidade de Rawls. O primeiro diz que "cada pessoa deve ter um direito igual ao mais abrangente sistema total de liberdades básicas iguais que seja compatível com um sistema semelhante de liberdade para todos" (RAWLS, 1997, p.333). O segundo afirma que:

as desigualdades econômicas e sociais devem ser ordenadas de tal modo que, ao mesmo tempo: a) tragam o maior benefício possível para os menos favorecidos, obedecendo às restrições do princípio da poupança justa, e b) sejam vinculadas a cargos e posições abertos a todos em condições de igualdade equitativa de oportunidades (RAWLS, 1997, p.333).

Esses princípios estão condicionados a uma relação de prioridade, um princípio não pode suprimir o outro. Primeiro, a prioridade das liberdades básicas, posteriormente, a prioridade da igualdade, segundo os seus dois aspectos: por um lado, igualdade equitativa de oportunidades ou, por outro, diante das diferenças sociais e econômicas, é preciso operar em favor dos menos favorecidos. Este segundo momento do princípio de igualdade é o reconhecimento do princípio da diferença, que fundamenta a dimensão distributiva de sua teoria.

Esses princípios de justiça têm como objeto a estrutura básica da sociedade, as instituições políticas e sociais, que é o objeto primário da justiça, ou seja, o sujeito da teoria rawlsiana. Busca-se compreender "a maneira pela qual as instituições sociais mais importantes distribuem direitos e deveres fundamentais e determinam a divisão de vantagens provenientes da cooperação social” (RAWLS, 1997, p.7-8). Mas, o que entra na conta distributiva de Rawls?

\section{A métrica rawlsiana de distribuição está centrada na ideia de bens sociais primários, definidos como:}

direitos, liberdades e oportunidades, assim como renda e riqueza (...). A ideia principal é de que o bem de uma pessoa é determinado pelo que é para ela o mais racional plano de vida a longo prazo (...). Para resumir, o bem é a satisfação de um desejo racional. Devemos, supor, então, que cada indivíduo tem um plano racional delineado de acordo com as condições que se defronta (RAWLS, 1997, p.98).

Cada indivíduo é, portanto, portador de racionalidade e capaz de elaborar seu plano de vida no qual está contido a sua própria concepção de bem. Na teoria rawlsiana, não fazem sentido as comparações interpessoais de bem-estar, no sentido de medir o grau de satisfação, pois cada um constrói seu plano de vida, que é singular, que se torna legítimo na medida em que é compatível com os princípios de justiça e eficaz na medida em que é efetivado.

A teoria de justiça como concebida por Rawls é pensada tendo como base as sociedades livres e democráticas, como definida por ele, uma sociedade bem ordenada, na qual as instituições 
básicas operam a partir dos definidos princípios de justiça, que são reconhecidos e aceitos pelos seus membros. Esses são os termos centrais sob os quais Rawls fundou sua teoria, alguns deles tornaram-se objeto de grandes polêmicas junto aos seus críticos.

No âmbito do liberalismo igualitário, Ronald Dworkin (2012) elaborou algumas críticas pontuais à teoria rawlsiana, embora seu pensamento tenha muitas convergências com a mesma. Diferentemente de Rawls, que, ao tratar da igualdade, afirma a necessidade da distribuição igual de bens sociais primários, Dworkin a trata como igualdade de consideração, pois os indivíduos devem ser tratados como iguais. É preciso que haja igualdade na distribuição dos recursos impessoais. Como fazer divisão igualitária de recursos? Logo, ele traz para o cerne de sua análise a importância do mercado. "É claro que é supremo nesse argumento, e nessa conexão entre o mercado e a igualdade de recursos, que as pessoas entrem no mercado em igualdade de condições (DWORKIN, 2012, p.87). A partir daí os indivíduos possuem liberdade para fazerem suas escolhas, assim como também assumirem individualmente suas consequências. A política distributiva para ele direciona-se somente para aqueles que sofrem carências devido à sorte bruta, ocasionadas por circunstâncias não programadas. Os resultados advindos da sorte por opção, ou seja, das escolhas dos indivíduos, é responsabilidade deles próprios. Nesse ponto reside a crítica dele a Rawls. A falha identificada na concepção rawlsiana de justiça é que a questão da responsabilidade individual não é levada a sério, já que, sob o véu de ignorância, os gostos e as liberdades de cada um não são considerados.

Ainda no interior da teoria liberal, Robert Nozick (1991), associado ao libertarismo, refutou a teoria rawlsiana. Ele não concebe uma teoria capaz de articular liberdade e igualdade, já que, para ele, esses valores são antagônicos. $\mathrm{O}$ autor parte da premissa de que os indivíduos são livres para fazerem o que quiserem com suas vidas e seus bens, e que são também individualmente responsáveis pelas suas consequências. O único limite que se impõe é a existência do outro. A teoria que elabora não trata da justiça na perspectiva dos direitos sociais, mas sim, da liberdade individual. Há a necessidade do Estado, porém este não surge a partir de um contrato, como ocorre na perspectiva rawlsiana. Na teoria do justo título ou da titularidade de Nozick, o Estado deve ser ultra mínimo, ou seja, proteger os direitos morais ligados às individualidades. Prevê, portanto, a garantia dos direitos civis.

Cohen (2008), a partir do marxismo analítico, entendido como uma filosófica política normativa de base socialista, elabora sua crítica à teoria rawlsiana no que tange ao segundo princípio estabelecido, o da igualdade. Para ele esse princípio é conivente com condições de desigualdade que são inaceitáveis para o socialismo. Os princípios de justiça, em vez de atuarem junto às estruturas básicas, deveriam compor, em sua perspectiva, as escolhas das pessoas. Assim, estabelece como sua métrica a igualdade de oportunidade de acesso à vantagem.

A crítica elaborada pelos comunitaristas também trouxe grandes contribuições para o debate acerca da teoria de justiça de Rawls. Esse debate será empreendido no próximo tópico, através do multiculturalismo de Charles Taylor.

\section{O multiculturalismo de Taylor: uma vertente do comunitarismo}

As discussões acerca da concepção de justiça balizadas entre a perspectiva normativa de base liberal, principalmente no âmbito do liberalismo igualitário, e a perspectiva comunitarista ganharam muita notoriedade na teoria política contemporânea. O termo comunitarismo possui diferentes significados. Na língua inglesa, esteve, no século XIX, associado a doutrinas 
socialistas e ainda hoje continua guardando relação com a defesa dos socialmente destituídos. No alemão, diferentemente, esteve associado aos movimentos nacionalistas, até mesmo ao próprio nazismo (FERES JÚNIOR, 2010). Guardando as particularidades do uso que se fez, o seu significado gira em torno da valorização da solidariedade e dos valores partilhados por indivíduos pertencentes a uma coletividade.

Para além dessa acepção geral, o comunitarismo, enquanto pensamento político, possui também uma dimensão normativa, ou seja, se preocupa em pensar como deveria se constituir um arranjo societário mais eficaz no que se refere à promoção do bem comum. Suas premissas se colocam claramente contrárias às vertentes da corrente dominante, o liberalismo. Enquanto, para este, "o indivíduo e a autonomia individual são pilares inamovíveis, e a comunidade acaba sendo vista como um produto de ações, interesses, ou escolhas individuais (...)" (FERES JÚNIOR, 2010, p.93), para os comunitaristas, “os indivíduos nessa concepção são vistos como produtos de sistemas de valores e práticas sociais estabelecidas, sem os quais a existência individual não teria conteúdo ou sentido" (Idem).

O multiculturalismo, que surge como uma vertente do comunitarismo, entrou no debate da teoria política contemporânea devido à necessidade de se pensar a adequação das instituições democráticas às sociedades complexas e plurais da contemporaneidade. Como afirma Feres Júnior:

O próprio comunitarismo, para se colocar em sintonia com as sociedades complexas sobre as quais seus autores estão escrevendo, teve que tematizar o multiculturalismo (...). Em grande medida porque o comunitarismo fundamenta a moral (...) e a justiça no sentimento de pertencimento comum e história partilhada de uma sociedade. Assumir de pronto o princípio normativo de que uma sociedade complexa do presente deva ter um e somente um sistema de valores, uma e somente uma narrativa histórica, uma e somente uma comunidade, é altamente problemático dada a realidade nua e crua da diversidade de modos de vida que compõem essas sociedades (...) (2010, p.89).

O debate acerca do multiculturalismo surge em meio à necessidade de se pensar a diversidade existente nas sociedades contemporâneas, que resultam, por conseguinte, em uma pluralidade de sistemas de valores. A perspectiva multicultural possui uma especificidade no sentido de que, além das discussões travadas internamente à academia - no campo da teoria política, foi também muito problematizada em outras áreas, como nas pautas dos movimentos sociais, nas teorias feminista, foucaultiana e pós-colonial (FERES JÚNIOR, 2010). No cerne de todas essas críticas, está o questionamento do projeto iluminista de democracia liberal, de base universalista, que tem como referência um sujeito abstrato.

No âmbito deste trabalho, não é possível retomar todo esse conjunto de críticas - oriundas tanto do âmbito acadêmico, quanto internamente, nos movimentos sociais - feitas ao projeto iluminista construtor desse sujeito universal e abstrato. No entanto, é importante ressaltar que tais críticas foram elaboradas por diferentes intelectuais, pertencentes a diferentes perspectivas teóricas. Um deles, o economista Joseph Schumpeter, um dos intelectuais representantes da teoria das elites, dirige sua crítica a esse caráter universal do sujeito. Em sua acepção, não existe um sujeito universal, portanto, se não é possível pensar uma unidade no que se refere aos sujeitos, também não o é em relação as suas vontades. As vontades são também divergentes, o que põe em discussão a ideia do "bem comum". 
Não há, para começar, um bem comum inequivocamente determinado que o povo aceite ou que possa aceitar por força de argumentação racional. Não se deve isso primariamente ao fato de que as pessoas podem desejar outras coisas que não o bem comum, mas pela razão muito mais fundamental de que, para diferentes indivíduos e grupos, o bem comum provavelmente significará coisas muito diversas (SCHUMPETER, 1961, p.307).

Ao afirmar a impossibilidade de se pensar a democracia a partir da ideia do bem comum, esse autor acaba desvelando, em seu pensamento, um horizonte em que as diferenças são elementos importantes e que devem ser considerados quando se pensa a democracia. Porém, não é otimista no que se refere à vontade do indivíduo ou vontade do cidadão, pois não vê este como portador de "independência" e de "qualidade racional", necessárias para se pensar as questões políticas - e, mesmo que o cidadão comum possuísse tais qualidades, suas vontades são muito divididas. Dessa incapacidade atribuída ao cidadão comum de pensar as questões políticas, assim como também de determinar os seus processos decisórios, é que deriva a concepção reduzida de Schumpeter acerca da democracia. Segundo essa concepção, ao eleitor cabe apenas escolher seu representante através do voto, ou seja, constituir o governo. Esse momento de escolha dos representantes é secundário em sua teoria, enquanto que o elemento central reside na tomada de decisões, feitas pelos representantes escolhidos. Assim, "o método democrático é um sistema institucional, para a tomada de decisões políticas, na qual o indivíduo adquire o papel de decidir mediante uma luta competitiva pelos votos do eleitor" (SCHUMPETER, 1961, p.328). Essas são as "regras do jogo" democrático, no qual a aceitação das mesmas é fundamental para a construção do consenso, no que se refere aos meios, que resultará na continuidade do mesmo jogo.

A democracia é concebida, portanto, enquanto método de seleção dos representantes, e aí se esgota para Schumpeter a participação dos indivíduos. Dessa forma, apesar de esse autor fazer a crítica da ideia de universalidade que está na base da teoria democrática clássica, acaba construindo uma teoria da democracia conservadora ao não dar conta de pensar a antítese do que seria essa universalidade, a problemática da diferença.

Chantal Mouffe (1996) também problematizou essa questão, embora compartilhe com Schumpeter apenas o ponto de partida, a crítica ao referido sujeito iluminista, já que propõe a "redefinição do jogo". Em sua crítica à teoria democrática clássica, ela afirma a necessidade de resgatar a especificidade do político no que se refere à apreensão do papel constitutivo dos antagonismos sociais. Na democracia moderna, não é mais possível conviver com as generalizações das identidades - o que vale para todos os seus "elementos", seja no âmbito das questões de gênero, sexualidade, étnico, dentre outros. Segue dizendo que, "no dealbar do século XXI, as nossas sociedades estão a sofrer um profundo processo de redefinição das suas identidades coletivas e a experimentar o estabelecimento de novas fronteiras políticas" (MOUFFE, 1996, p.14). Ela está afirmando a necessidade da criação e da manutenção de uma ordem democrática e pluralista.

O rompimento com o racionalismo, o individualismo e o universalismo é a base para a construção do que denominou de democracia radical e plural, que, segundo Mouffe, se traduz na necessidade de aprofundamento da revolução democrática.

Só nessa condição será possível apreender a multiplicidade de formas de sujeição que existem nas relações sociais e facultar um enquadramento para a articulação das diferentes lutas democráticas - em torno do gênero, da raça, da classe, do sexo, do ambiente e de outros fatores (MOUFFE, 1996, p.18). 
A modernidade é a gestora da revolução democrática. Essa autora reafirma a importância do projeto político da revolução democrática, que sinaliza para a necessidade de liberdade e igualdade para todos os indivíduos. No entanto, no projeto da democracia radical, nega o sujeito abstrato e unitário do projeto iluminista. O sujeito de que fala Mouffe é "um sujeito construído no ponto de intersecção de uma multiplicidade de posições subjetivas" (p.26).

Quem é esse novo sujeito? Quais processos fizeram com que ele entrasse em cena? Hall (2001) lança luz a essas questões ao problematizar três concepções diferentes de identidade. A primeira, identidade "do sujeito iluminista", a qual já foi extensamente problematizada acima, é alvo de críticas, pois a identidade é vista como elemento pertencente a um núcleo interior do sujeito, portanto a concebe de maneira fixa e essencialista. A segunda, a "do sujeito sociológico", se distancia dessa perspectiva individualista de identidade, já que a mesma é construída de maneira relacional, isto é, é sempre uma negociação entre o eu e a sociedade. "A identidade, então, costura (ou, para usar uma metáfora médica "sutura") o sujeito à estrutura" (HALL, 2006, p.12). E, por fim, a identidade "do sujeito pós-moderno", resultante das mudanças ocorridas na contemporaneidade ou, segundo ele, na modernidade tardia.

As sociedades da modernidade tardia, argumenta ele [Laclau], são caracterizadas pela "diferença"; elas são atravessadas por diferentes divisões e antagonismos sociais que produzem uma variedade de diferentes "posições do sujeito" - isto é, identidades - para os indivíduos. (HALL, 2006, p.17).

O sujeito do qual falamos é, portanto, o sujeito pós-moderno, que se constitui paralelamente ao processo, identificado por Hall como descentramento do sujeito iluminista. As discussões feitas pelo multiculturalismo vão ao encontro dessas prerrogativas, pois são esses os sujeitos que se tornaram seu objeto de estudo. Mas há todo um processo de resgate desses sujeitos. É preciso problematizar as condições de existência e os processos de resistência e luta por direitos desses grupos que foram atravessados e cindidos por esse olhar homogeneizante, construído pelas teorias democráticas clássicas, o qual resultou em um processo de exclusão e marginalização de diversos grupos. Charles Taylor se insere nesse debate, a partir da retomada do conceito de reconhecimento, que coloca as discussões acerca da teoria normativa sob novo ângulo de análise.

No lugar dessa ideia influente de justiça, que pode ser vista em termos políticos como manifestação da era da democracia social, parece ter surgido uma ideia nova que, a princípio, parece politicamente um tanto ou quanto menos inequívoca. Seu objetivo normativo não mais parece a eliminação da desigualdade, mas a anulação da degradação e do desrespeito; suas categorias centrais não são mais a "distribuição igual" ou a "igualdade econômica", mas a "dignidade" e "respeito". Nancy Fraser forneceu uma fórmula suscinta, quando se referiu a essa transição como uma passagem da "redistribuição para o "reconhecimento". Enquanto o primeiro conceito está ligado a uma visão de justiça, que visa alcançar a igualdade social através de uma redistribuição das necessidades materiais para a existência dos seres humanos enquanto sujeitos livres, no segundo conceito, as condições para uma sociedade justa passam a ser definidas como o reconhecimento da dignidade pessoal de todos os indivíduos (HONNETH, 2007, p.79).

A busca pelo reconhecimento necessariamente passa pelas discussões acerca da identidade, pois, como afirma Taylor, "a tese consiste no fato de a nossa identidade ser formada, em parte, pela existência ou inexistência de reconhecimento e, muitas vezes, pelo reconhecimento incorreto dos outros" (TAYLOR, 1994, p.45), o que pode resultar em processos de exclusão ou marginalização de minorias, assim como também no processo de autodepreciação. 
O ponto de partida de Taylor para discutir reconhecimento e identidade é a análise acerca do deslocamento da noção de honra, predominante nas sociedades monárquicas, que hierarquizavam os indivíduos, atribuindo-lhes status sociais desiguais, pela noção moderna de dignidade.

Naturalmente, este conceito de dignidade é o único que é compatível com a sociedade democrática, e era inevitável que pusesse de lado o velho conceito de honra. Um exemplo disso é o tratamento generalizado de "Mr.", "Mrs.", ou "Miss", em vez de "Lord" ou "Lady", ou, então, pelos apelidos - ou, ainda mais baixo, pelos nomes cristãos -, considerando essencial para algumas sociedades democráticas, como é o caso dos Estados Unidos. Recentemente, e por razões semelhantes, "Mrs." e "Miss" deram lugar a "Ms.". A democracia introduziu a política do reconhecimento igualitário, que tem assumido várias formas ao longo dos anos, e que regressou agora sob a forma de exigências de um estatuto igual para as diversas culturas e para os sexos (TAYLOR, 1994, p. 47,48).

A identidade do sujeito não é mais determinada pela posição social que ocupa, mas sim, a partir da noção de identidade individualizada, ligada à noção de autenticidade. Essa mudança na forma de conceber as identidades é resultante de uma nova forma de conceber o próprio sujeito e sua subjetividade na sociedade moderna, de forma mais específica, a partir do final do século XVIII. Taylor (1994) retoma Rousseau e Herder ao problematizar essa questão. Para os propósitos deste trabalho, o importante a salientar é que, ao acionar a categoria de originalidade, está se afirmando que "existe uma determinada maneira de ser humano que é minha maneira” (TAYLOR,1994, p.50), que é única. Nessa chave de leitura, a aplicação da categoria de originalidade é útil para fundamentar duas grandes críticas à modernidade: a primeira, a uma dimensão individual, na qual a categoria de "ser humano", tratado de maneira abstrata, deixa de fazer sentido, e a segunda, ao colonialismo europeu, , ao impor às nações colonizadas sua própria cultura, em nome do processo civilizatório, promoveu o processo de hierarquização das culturas, portanto, destituindo-lhes de sua originalidade.

A originalidade aparece como elemento constituinte da identidade, porém, não a completa, pois a mesma se constrói em uma relação dialógica. "As pessoas não aprendem sozinhas as linguagens necessárias à autodefinção. Pelo contrário, elas são-nos dadas a conhecer através da interação com aqueles que são importantes para nós - os 'outros importantes' como George H. Mead lhes chamou" (TAYLOR, 1994, p.52).

A identidade é, portanto, sempre resultado de uma negociação. Taylor chama a atenção para o fato de que a diferença entre a identidade de origem social e a identidade moderna é que, na primeira, o reconhecimento está associado a categorias sociais amplamente aceitáveis uma dependência em relação à sociedade, e a segunda, baseada na autenticidade, se constrói a partir de uma negociação constante com os outros. "É por isso que o desenvolvimento de um ideal de identidade gerada interiormente atribui uma nova importância ao reconhecimento" (TAYLOR, 1994, p.54).

No entanto, como exposto por Taylor, é com Hegel que a questão do reconhecimento ganha mais notoriedade. Ele discorre acerca de duas esferas distintas, ambas influenciadas pela noção de autenticidade, pelas quais o reconhecimento chega até os indivíduos: a esfera íntima, como já exposto acima, em que a identidade é construída de maneira dialógica, e a esfera pública, na qual se delineou a política de reconhecimento igualitário. Dito isso, vamos agora nos determos nessa segunda esfera, para analisarmos os dois significados assumidos por essa 
política de reconhecimento. Por um lado, a política do universalismo, que será problematizada associada à teoria de justiça rawlsiana, e, por outro, a política da diferença, sob a qual se funda o multiculturalismo de Taylor.

A política do universalismo, resultante do deslocamento do conceito de honra para dignidade, sofreu influência da filosofia kantiana. Para Kant, os indivíduos possuem status igual de dignidade pelo fato de serem todos racionais. A teoria de justiça de Rawls opera a partir dessa premissa. Além da liberdade, a igualdade é também estabelecida como princípio básico, que contém em si a dimensão de universalidade, dada a partir da igualdade equitativa de oportunidades, e também o reconhecimento do princípio da diferença ao definir que, diante de diferenças sociais e econômicas, deve-se operar em favor dos menos favorecidos. A questão que se coloca é: Quem são esses menos favorecidos para Rawls?

Ao elaborar sua teoria, Rawls afirma que seu objetivo principal era pensar uma teoria da justiça que fosse a mais compatível com as sociedades contemporâneas. Ele estava, portanto, levando para o cerne de suas teorizações a complexidade e a pluralidade, que são as características centrais de nossas sociedades. No entanto, isso é alvo de muitas críticas, pois o menos favorecido não tem gênero, etnia, sexualidade. Essa perspectiva acaba sendo acusada de ser um particularismo disfarçado de universalismo, como afirma Taylor. As críticas dirigidas a esse "sujeito iluminista" estão pautadas na ideia de que, em última instância, esse sujeito é homem, ocidental, branco, heterossexual e monogâmico.

A verdade é que existem formas deste liberalismo e de direitos igualitários que, nas mentes dos seus próprios defensores, só permitem que se admita, de forma muito restrita, as identidades culturais distintas. A noção de que qualquer lista de direitos poderia ter uma aplicação diferente consoante os contextos culturais, de que as suas aplicações poderiam ter de considerar diferentes objetivos coletivos, é tida como totalmente inaceitável (TAYLOR, 1994, p.72).

Formulações como a teoria rawlsiana de justiça são vistas, nessa perspectiva, como incapazes de dar conta da diversidade cultural, já que produziram um processo de exclusão e marginalização de diversos grupos. Taylor afirma que, para além da sobrevivência das culturas, a exigência que se faz a partir de agora é reconhecer seu valor. A política da diferença ${ }^{4}$ que influencia o seu pensamento, que também tem base universalista, parte do princípio de que "todas as pessoas devem ser reconhecidas pelas suas identidades únicas” (TAYLOR, 1994, p.58). Assim, o elemento universalizante se constitui sob outras bases, pois, ao se encerrar no reconhecimento dos indivíduos enquanto portadores de identidades únicas, dá margem para que os indivíduos e grupos definam suas próprias identidades - os indivíduos são vistos como agentes sociais. Como esse autor afirma, "a noção de identidade nos traz como referência certas avaliações que são essenciais, pois são elas que definem o fundamento ou o horizonte indispensável a partir do qual nos tornamos pessoas que refletem e avaliam" (TAYLOR, 2007, p.30).

A perspectiva multicultural parte do princípio de que é preciso corrigir processos em que, como exposto acima, as diferenças têm sido ignoradas ou diluídas na identidade dominante, processos estes que resultaram no não reconhecimento ou reconhecimento incorreto desses sujeitos/identidades coletivos. Como afirma Mattos (2007), a relação entre identidade e

\footnotetext{
Honneth (2007) afirma que é errônea a interpretação, feita por Taylor, de que a luta por reconhecimento é algo muito recente. Assim como também é errôneo e simplificador reduzir tais lutas ao aspecto do reconhecimento cultural. Não entraremos no mérito da questão, já que nos limitamos, neste trabalho, à crítica de Charles Taylor.
} 
moralidade presente no pensamento tayloriano traz uma discussão importante nesse sentido, pois, como afirma Mattos (2007), problematiza o naturalismo e suas tentativas de construção da ideia de neutralidade por trás das instituições.

O naturalismo opera propagando a ideia de um conceito de ação humana ou de self objetificado, livre de suas autointerpretações morais, tidas como fontes de autoengano. É a partir do naturalismo que é possível se defender que as instituições modernas são neutras, baseadas em critérios meritocráticos e igualitários. A denúncia de Taylor é de que as instituições e as práticas sociais sempre reproduzem uma concepção pré-reflexiva de boa vida, uma hierarquia moral que está na base de nossas autointerpretações e das interpretações que fazemos da sociedade que vivemos (MATTOS, 2007, p.51).

Assim, ao contrário do que pressupõe essa perspectiva naturalista, Taylor direciona seu olhar para o fato de que, por trás de tais instituições, sempre haverá um conteúdo moral. Daí a importância das discussões realizadas no âmbito do multiculturalismo e, nesse caso, a partir do pensamento de Charles Taylor, pois sua perspectiva, centrada na política do reconhecimento, via valorização da diferença, trabalha, em sua base, com uma pluralidade moral, apreendida no interior das diferentes identidades dos sujeitos e das coletividades.

\section{Considerações finais}

À guisa de conclusão, apresentamos o seguinte questionamento: é possível o diálogo entre a teoria da justiça rawlsiana e o multiculturalismo de Charles Taylor? A relação entre, por um lado, a política da universalidade - a qual segundo Feres Júnior (2010), propõe a redistribuição material que é operada em nome de uma reversão de processos de discriminação e exclusão - e, por outro, a política do reconhecimento - que opera em favor de medidas especiais de proteção das diferenças culturais existentes entre os indivíduos e grupos - torna, por vezes, tenso e, talvez, poderíamos dizer até mesmo insolúvel o diálogo entre liberalismo (igualitário) e multiculturalismo (comunitarismo). Isto porque as teorias de bases liberais, como a teoria da justiça de Rawls, são acusadas de homogeneidade, e esta análise decorre do fato de que em nome de uma suposta neutralidade as sociedades ocidentais têm imposto historicamente a sua própria cultura às demais sociedades. Enquanto as teorias multiculturais reconhecem as especificidades das culturas, mas acabam, muitas vezes, por se perderem em meio aos seus subjetivismos. 


\section{Referências}

ARISTÓTELES. Ética a Nicômaco. 6. ed. São Paulo: Martin Claret, 2013.

COHEN, G. A. Rescuing justice and equality. London: Harvard University, 2008.

DWORKIN, Ronald. A virtude soberana. São Paulo: Martins Fontes, 2012.

FERES JÚNIOR, João. Teoria política contemporânea: uma introdução. Rio de Janeiro: Elsevier, 2010.

HALL, Stuart. A identidade cultural na pós-modernidade. 6ª ed. Rio de Janeiro: DP\&A, 2001.

HALL, Stuart. Da diáspora: identidades e mediações culturais. Belo Horizonte: Editora da UFMG, 2003.

HONNETH, Axel. Reconhecimento ou redistribuição? A mudança de perspectivas na ordem moral da sociedade. In. SOUZA, J.; MATTOS, P. (Org.). Teoria crítica no século XXI. São Paulo: Annablume, 2007.

MATTOS, Patrícia. O reconhecimento social e suas refundações filosóficas em Charles Taylor. In. SOUZA, J.; MATTOS, P. (Org.). Teoria crítica no século XXI. São Paulo: Annablume, 2007.

MOUFFE, Chantal. O regresso do político. Lisboa: Gradiva, 1996.

NOZICK, Robert. Anarquia, Estado e utopia. São Paulo: Jorge zahar, 1991.

RAWLS, John. Uma teoria da justiça. São Paulo: Martins Fontes, 1997.

SCHUMPETER, Joseph A. Capitalismo, socialismo e democracia. Rio de Janeiro: Editora Fundo de Cultura, 1961.

SILVA, José Afonso da. Curso de direito constitucional positivo. São Paulo: Malheiros, 2000.

TAYLOR, Charles. Multiculturalismo. Lisboa: Instituto Piaget, 1994.

TAYLOR, Charles. O que é agência humana? In. SOUZA, J.; MATTOS, P. (Org.). Teoria crítica no século XXI. São Paulo: Annablume, 2007. 